\title{
Mechanisms of Fatty Acid-induced Inhibition of Glucose Uptake
}

\author{
Guenther Boden, ${ }^{*}$ Xinhua Chen, ${ }^{\star}$ Jose Ruiz, ${ }^{*}$ John V. White, ${ }^{\star}$ and Luciano Rossetti \\ ${ }^{*}$ Division of Endocrinology/Metabolism, ${ }^{\ddagger}$ Department of Surgery, and the General Clinical Research Center, Temple University School \\ of Medicine, Philadelphia, Pennsylvania 19140; and ${ }^{\S}$ Division of Endocrinology/Metabolism, Albert Einstein College of Medicine, \\ Bronx, New York 10461
}

\section{Abstract}

Increased plasma FFA reduce insulin-stimulated glucose uptake. The mechanisms responsible for this inhibition, however, remain uncertain. It was the aim of this study to determine whether the FFA effect was dose dependent and to investigate its mechanism. We have examined in healthy volunteers (13 male $/ 1$ female) the effects of three steady state plasma FFA levels $(\sim 50, \sim 550, \sim 750 \mu \mathrm{M})$ on rates of glucose uptake, glycolysis (both with $3-{ }^{3} \mathbf{H}$-glucose), glycogen synthesis (determined with two independent methods), carbohydrate (CHO) oxidation (by indirect calorimetry), hepatic glucose output, and nonoxidative glycolysis (glycolysis minus CHO oxidation) during euglycemic-hyperinsulinemic clamping. Increasing FFA concentration (from $\sim 50$ to $\sim 750 \mu \mathrm{M}$ ) decreased glucose uptake in a dose-dependent fashion ( from $\sim 9$ to $\sim 4 \mathrm{mg} / \mathrm{kg}$ per $\mathrm{min})$. The decrease was caused mainly $(\sim 2 / 3)$ by a reduction in glycogen synthesis and to a lesser extent $(\sim 1 / 3)$ by a reduction in $\mathrm{CHO}$ oxidation. We have identified two independent defects in glycogen synthesis. The first consisted of an impairment of muscle glycogen synthase activity. It required high FFA concentration $(\sim 750 \mu \mathrm{M})$, was associated with an increase in glucose-6-phosphate, and developed after 4-6 h of fat infusion. The second defect, which preceded the glycogen synthase defect, was seen at medium $(\sim 550 \mu M)$ FFA concentration, was associated with a decrease in muscle glucose-6-phosphate concentration, and was probably due to a reduction in glucose transport/phosphorylation. In addition, FFA and/or glycerol increased insulin-suppressed hepatic glucose output by $\sim 50 \%$. We concluded that fatty acids caused a dose-dependent inhibition of insulin-stimulated glucose uptake (by decreasing glycogen synthesis and CHO oxidation) and that FFA and / or glycerol increased insulin-suppressed hepatic glucose output and thus caused insulin resistance at the peripheral and the hepatic level. (J. Clin. Invest. 1994. 93:24382446.) Key words: glycogen synthesis • glycolysis • carbohydrate oxidation • glycogen synthase $\bullet$ glycogen phosphorylase

\section{Introduction}

Inability of insulin to appropriately promote glucose uptake in skeletal muscle (insulin resistance) has been recognized as an

Address correspondence to Guenther Boden, M.D., Temple University Hospital, 3401 North Broad Street, Philadelphia, PA 19140.

Received for publication 19 November 1993 and in revised form 7 February 1994

J. Clin. Invest.

(c) The American Society for Clinical Investigation, Inc. 0021-9738/94/06/2438/09 \$2.00

Volume 93, June 1994, 2438-2446 early and prevalent abnormality in non-insulin-dependent diabetes mellitus (NIDDM) ${ }^{1}$ (for review see reference 1 ). While its cause remains uncertain, insulin resistance is known to be commonly associated with an inability of insulin to normally promote nonoxidative glucose disposal (glucose storage) and to activate skeletal muscle glycogen synthase (GS) (2-9). There is evidence to suggest that in many instances the defects in glucose uptake and storage may be related to abnormal fat metabolism $(10,11)$. First, most patients with NIDDM are obese and have elevated blood FFA concentrations (12), which have been shown to inhibit insulin-stimulated glucose uptake (13-17). The issue of whether or not FFA inhibit glucose uptake has remained somewhat controversial since some investigators have failed to find such an effect $(18,19)$. We have demonstrated recently, however, that the fatty acid-mediated inhibition of insulin-stimulated glucose uptake only developed after 3-4 h of fat infusion (15). It is therefore likely that insufficient length of fat infusion was the reason why the inhibitory effect of FFA on glucose uptake was not found in some studies. Second, Gulli et al. (20) have recently shown in offspring of parents with NIDDM, known to be at high risk to develop the disease $(7,8)$, that impaired insulin-stimulated glucose uptake and storage were associated with elevated fatty acid levels and oxidation. Third, fat infusion has recently been shown to be associated with suppression of insulin-stimulated skeletal muscle GS activity $(15,16)$. It was not clear from these studies, however, whether the observed GS defect was responsible for the inhibition of glucose uptake. GS activities were measured only before and after but not during fat infusions; thus, it remained unknown whether the GS defect preceded, coincided with, or followed the inhibition in glucose uptake. Moreover, glycogen synthesis, which does not always correlate with GS activity (21), was not measured. The aim of this study was therefore to determine whether the fatty acid effects were dose dependent and to elucidate their mechanisms by examining FFA actions on all major pathways of intracellular glucose utilization. To this end, we have examined effects of three steady state fatty acid levels $(\sim 50, \sim 550, \sim 750 \mu \mathrm{M})$ on rates of glucose uptake, glycolysis, glycogen synthesis, carbohydrate (CHO) oxidation, nonoxidative glycolysis (lactate/alanine fluxes), and on hepatic glucose output (HGO) in healthy volunteers during euglycemic hyperinsulinemia.

\section{Methods}

\section{Subjects}

14 healthy, normal weight volunteers ( 13 men and 1 woman) were studied. We were unable to recruit more women, largely because of the

1. Abbreviations used in this paper: $\mathrm{CHO}$, carbohydrate; FFM, fat free mass; G-6-P, glucose-6-phosphate; $\mathrm{G}_{\mathrm{Rd}}$, glucose rate of disappearance; GS, glycogen synthase; HGO, hepatic glucose output; NIDDM, noninsulin-dependent diabetes mellitus; $\mathrm{npRQ}$, nonprotein respiratory quotient; PDH, pyruvate dehydrogenase; UDPG, uridine-diphosphate-glucose. 
need for four open muscle biopsies. The subjects' ages, weights, heights, and body compositions are shown in Table I. None of the subjects had a family history of diabetes or any other endocrine disorders, and none were taking any medications. Their weights were stable for at least 2 mo, their diets contained a minimum of $250 \mathrm{~g} / \mathrm{d}$ of carbohydrate for at least $2 \mathrm{~d}$ before the studies. Informed written consent was obtained from all after explanation of the nature, purpose, and potential risks of these studies. The study protocol was approved by the Institutional Review Board of Temple University Hospital. All subjects were admitted to Temple University Hospital's General Clinical Research Center on the evening before the studies. The studies began at $\sim 8 \mathrm{a} . \mathrm{m}$. after an overnight fast with the subjects reclining in bed. A short polyethylene catheter was inserted into an antecubital vein for infusion of test substances. Another catheter was placed into a contralateral forearm vein for blood sampling. This arm was wrapped with a heating blanket $\left(\sim 70^{\circ} \mathrm{C}\right)$ to arterialize venous blood. We have shown in preliminary experiments that this results in near identical arterial and venous forearm blood glucose concentrations (Boden, G., unpublished observations).

\section{Experimental design}

Study 1 (high fatty acids). Four subjects were studied in this protocol. 3- ${ }^{3} \mathrm{H}$-glucose was infused intravenously for $7.5 \mathrm{~h}$ ( -90 to $\left.360 \mathrm{~min}\right)$ starting with a bolus of $40 \mu \mathrm{Ci}$ over $1 \mathrm{~min}$, followed by a continuous infusion of $0.4 \mu \mathrm{Ci} / \mathrm{min}$. At $0 \mathrm{~min}$, LIPOSYN II (Abbott Laboratories, North Chicago, IL) a $20 \%$ triglyceride emulsion (10\% safflower, $10 \%$ soy bean oil $)$ plus heparin $(0.4 \mathrm{U} / \mathrm{kg}$ per $\mathrm{min})$ were infused at a rate of $1.5 \mathrm{ml} / \mathrm{min}$ for $6 \mathrm{~h}$. Regular human insulin (Humulin R; Eli Lilly \& Co., Indianapolis, IN) was infused intravenously at a rate of $1 \mathrm{mU} / \mathrm{kg}$ per min for $6 \mathrm{~h}$ starting at $0 \mathrm{~min}$. Glucose concentrations were clamped at $\sim 85 \mathrm{mg} / \mathrm{dl}$ by a feedback-controlled glucose infusion. The first muscle biopsy was performed before the start of the infusions (between -90 and $0 \mathrm{~min}$ ), and the other three biopsies were performed at 120 , 240 , and $360 \mathrm{~min}$, respectively.

Study 2 (medium fatty acids). Four subjects were studied in this protocol, which was identical to study 1 except that LIPOSYN II was infused without heparin.

Study 3 (low fatty acids). Six subjects were studied. All six received insulin and glucose as in studies 1 and 2 . Three received, in addition, glycerol $(0.7 \pm 0.05 \mathrm{mg} / \mathrm{kg}$ per $\mathrm{min})$ plus heparin $(0.4 \mathrm{U} / \mathrm{kg}$ per $\mathrm{min})$ to simulate glycerol and heparin infusions in study 1 (LIPOSYN II contains $2.14 \mathrm{~g}$ glycerol $/ 100 \mathrm{ml}$ as emulsifier). The additional infusion of glycerol and heparin had no effect on any of the metabolic parameters measured including serum concentrations of glucose, insulin, and glucagon and rates of glucose appearance, oxidation, glycolysis, and glycogen synthesis. The data from the studies with and without glycerol plus heparin were therefore combined.

\section{Glucose turnover}

Glucose turnover was determined with $3-{ }^{3} \mathrm{H}$-glucose. The tracer infusion was started $90 \mathrm{~min}$ before initiation of the clamp to assure isotope equilibration. Glucose was isolated from blood for determination of $3-{ }^{3} \mathrm{H}$-glucose specific activity as described (22). Changes in specific activity during hyperinsulinemia were avoided by adding $3-{ }^{3} \mathrm{H}$-glucose to the unlabeled glucose, which was infused at variable rates to main-

Table I. Characteristics of Study Subjects

\begin{tabular}{lccc}
\hline & $\begin{array}{c}\text { Study } 1 \\
\text { (high fatty acids) }\end{array}$ & $\begin{array}{c}\text { Study 2 } \\
\text { (medium fatty acids) }\end{array}$ & $\begin{array}{c}\text { Study } 3 \\
\text { (low fatty acids) }\end{array}$ \\
\hline Sex $(M / F)$ & $4 / 0$ & $4 / 0$ & $5 / 1$ \\
Age $(y r)$ & $24.2 \pm 2.8$ & $31.0 \pm 3.0$ & $26.5 \pm 2.0$ \\
Height $(\mathrm{cm})$ & $182.9 \pm 2.9$ & $177.2 \pm 3.6$ & $173.0 \pm 3.5$ \\
Weight $(\mathrm{kg})$ & $83.3 \pm 8.2$ & $82.9 \pm 4.6$ & $68.5 \pm 3.6$ \\
FFM $(\mathrm{kg})$ & $70.8 \pm 8.1$ & $70.3 \pm 3.9$ & $60.3 \pm 3.6$
\end{tabular}

tain euglycemia (23). Rates of total body glucose appearance and disappearance $\left(G_{R d}\right)$ were calculated using Steele's equation for steady state conditions (24). As seen in Fig. 1, serum $3-{ }^{3} \mathrm{H}$-glucose specific activities were at steady state for all three groups and for the entire length of the studies except for minor changes during the initial $90 \mathrm{~min}$.

\section{Glycolytic flux}

Glycolytic flux was determined according to Rossetti and Giaccari with minor modifications (25). Tritium in the 3-carbon position of glucose is lost into water during glycolysis. Recently, we have validated the assumption that the rate of plasma tritiated water formation reflects the intracellular detritiation of $3-{ }^{3} \mathrm{H}$-glucose (26). The rate of glycolysis was obtained by dividing the whole body ${ }^{3} \mathrm{H}_{2} \mathrm{O}$ production rate by the specific activity of its precursor, i.e., plasma $3-{ }^{3} \mathrm{H}$-glucose. To calculate the ${ }^{3} \mathrm{H}_{2} \mathrm{O}$ production rate, the time course of the plasma ${ }^{3} \mathrm{H}_{2} \mathrm{O}$ concentration was plotted vs time, and the slope of the linear regression was estimated by the least square method. The whole body production rate was obtained by multiplying this value with the body water volume measured in each study subject. Total body water occupies $~ 73 \%$ of fat free mass (FFM) (26). The latter was determined by underwater weighing (27).

\section{Glycogen synthesis}

Glycogen synthesis was quantitated by two independent methods. First, because net glycogen synthesis is the portion of glucose flux not entering glycolysis, whole body glycogen synthesis rates were obtained by subtracting rates of glycolysis from rates of glucose uptake $\left(G_{R d}\right)$. We have documented the validity of this noninvasive approach by demonstrating in healthy humans that results obtained with this method were comparable with rates of glycogen synthesis determined by incorporation of tritium from $3-{ }^{3} \mathrm{H}$-glucose into muscle glycogen. Second, rates of glycogen formation were calculated on the basis of in vitro muscle GS activity determined with actually measured muscle concentrations of glucose-6-phosphate (G-6-P) and uridine-diphosphate-glucose (UDPG) (26). Glycogen synthesis per unit muscle was extrapolated to whole body glycogen synthesis, assuming that $52 \%$ of FFM was muscle (26).

\section{$\mathrm{CHO}$ and lipid oxidation}

$\mathrm{CHO}$ and lipid oxidation were determined by indirect calorimetry as described (28) with a metabolic measurement cart (Beckman Instruments, Inc., Palo Alto, CA ). Rates of protein oxidation were estimated from urinary $\mathrm{N}$ excretion after correction for changes in urea $\mathrm{N}$ pool size (29). Rates of protein oxidation were used to determine the nonprotein respiratory quotient ( $\mathrm{npRQ}$ ). It was assumed that for each gram of $\mathrm{N}$ excreted in the urine, 6.02 liters of $\mathrm{O}_{2}$ were consumed, and

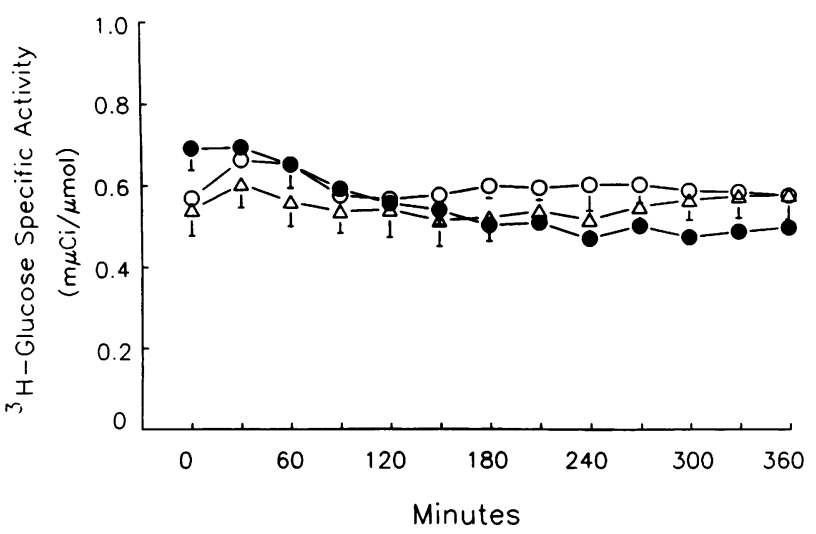

Figure 1. ${ }^{3} \mathrm{H}$-Glucose specific activities. $3-{ }^{3} \mathrm{H}$-glucose specific activities during euglycemic-hyperinsulinemic clamping at high (open triangles, $n=4$ ), medium (open circles, $n=4$ ), and low FFA concentrations (filled circles, $n=6$ ). Shown are mean \pm SE. 
4.75 liters of $\mathrm{CO}_{2}$ were produced $(\mathrm{RQ}=0.79)$. Rates of $\mathrm{CHO}$ and fat oxidation were determined with the npRQ tables of Lusk, which are based on an npRQ of 0.707 for $100 \%$ fat oxidation and 1.00 for $100 \%$ CHO oxidation.

\section{Muscle biopsies and extractions}

Biopsies were obtained from the lateral aspect of the vastus lateralis muscle $\sim 15 \mathrm{~cm}$ above the patella from all subjects as described (15). The excised muscle sample ( $\sim 150 \mathrm{mg}$ ) was dropped immediately into isopentane, kept at its freezing point $\left(-160^{\circ} \mathrm{C}\right)$ by liquid nitrogen. The frozen muscle was stored at $-80^{\circ} \mathrm{C}$ until it was aliquoted for measurement of GS, G-6-P/UDPG, and glycogen phosphorylase.

\section{Metabolite assays}

Muscle UDPG concentration was measured after two sequential chromatographic and HPLC separations and ultraviolet detection, as reported previously (26). Briefly, the first is performed on a solid-phase, strong anion exchange cartridge, with the use of phosphate buffers of increasing molarity. This first purification allows one to partially separate the compound of interest from all nonpolar and most of the polar intracellular substrates with optimal recoveries. The second step is a reversed-phase, ion-pairing HPLC isocratic method on a $\mathrm{C}_{18 \mathrm{~T}}$ column (Supelco, Inc., Bellefonte, PA). Muscle G-6-P concentrations were measured spectrophotometrically as described by Michal (30).

\section{GS assay}

Muscle GS activity was measured by a modification $(31,32)$ of the method of Thomas et al. (33) and is based on the measurement of the incorporation of radioactivity into glycogen from UDP-[U- $\left.{ }^{14} \mathrm{C}\right]-$ glucose. Tissue samples $(7-12 \mathrm{mg})$ were homogenized in $1.0 \mathrm{ml}$ of Tris- $\mathrm{HCl}$ buffer, $\mathrm{pH} 7.8$, containing $10 \mathrm{mM}$ EDTA, $5 \mathrm{mM}$ DTT, 50 $\mathrm{mM} \mathrm{NaF}$, and $2.5 \mathrm{~g} /$ liter rabbit liver glycogen type III. The homogenate was centrifuged at $2,000 \mathrm{~g}$ for $15 \mathrm{~min}\left(\right.$ at $4^{\circ} \mathrm{C}$ ), and the supernatant was used for the GS assay by measuring the incorporation of UDP[U- ${ }^{14} \mathrm{C}$ ]glucose into glycogen at $37^{\circ} \mathrm{C}$. For the kinetic analysis, the assay was conducted at final concentrations of $0.005,0.025,0.050$, $0.125,0.50$, and $2.0 \mathrm{mM}$ UDPG and 0, 0.11, 0.22, and 7.2 mM G-6-P; the data were linearized as Eadie-Hofstee plots and fit using linear regression. The $K_{\mathrm{m}}$ for UDPG is the reciprocal of the slope, whereas the $V_{\max }$ is the y-intercept divided by the slope.

GS activity was calculated as micromoles of UDPG incorporated into glycogen per minute per milligram of protein and was expressed as $K_{\mathrm{m}}$, the concentration of UDPG at which GS activity was half maxi$\mathrm{mal}$, as $V_{\max }$, or as the fractional velocity of GS activity, i.e., the activity of GS at $0.1 \mathrm{mM} \mathrm{G-6-P} \mathrm{divided} \mathrm{by} \mathrm{the} \mathrm{activity} \mathrm{at} \mathrm{7.2} \mathrm{mM} \mathrm{G-6-P.} \mathrm{This} \mathrm{is}$ an indicator of the active form of GS and believed to be a sensitive parameter of in vivo GS activity (34).

\section{Glycogen phosphorylase assay}

Muscle glycogen phosphorylase activity was measured as described previously (31). This assay is based on the measurement of the incorporation of carbon-14 into glycogen from labeled glucose 1-phosphate. Glycogen phosphorylase $a$, the active phosphorylated enzyme, was assayed in the absence of AMP, and phosphorylase $b$, the total enzyme activity, was assayed in the presence of $5 \mathrm{mM}$ AMP. The tissue homogenates (7-12 $\mathrm{mg}$ ) were prepared as described above. The supernatant was used for glycogen phosphorylase assays by measuring the incorporation of $\left[{ }^{14} \mathrm{C}\right]$ glucose 1-phosphate into glycogen at $30^{\circ} \mathrm{C}$ in a mixture containing $33 \mathrm{mM}$ Mes, $200 \mathrm{mM} \mathrm{KF}, 0.45 \%$ mercaptoethanol, $15 \mathrm{mM}$ glucose 1-phosphate $(50 \mu \mathrm{Ci} / \mathrm{mmol})$, and $3.4 \mathrm{mg} / \mathrm{ml}$ glycogen. Phosphorylase $b$ was assayed in the same manner, except that the mixture contained $100 \mathrm{mM}$ glucose 1-phosphate $(6 \mu \mathrm{Ci} / \mathrm{mmol}), 13.4 \mathrm{mg} / \mathrm{ml}$ glycogen, and $5 \mathrm{mM}$ AMP.

\section{HGO}

HGO was calculated as the difference between glucose rate of appearance and the rate of glucose infused to maintain euglycemia during the clamps.
Nonoxidative glycolysis (lactate/alanine flux)

Nonoxidative glycolysis was calculated as the difference between rates of total body glycolysis and $\mathrm{CHO}$ oxidation.

\section{Leg blood flow}

Leg blood flow was determined every $30 \mathrm{~min}$ by venous occlusion plethysmography with a mercury strain gauge apparatus (model EC5R; Hokanson Inc., Issaquah, WA) (35).

\section{Body composition}

Body composition was determined by underwater weighing with correction for residual lung volume (27), which was determined after immersion in a sitting position with a closed circuit $\mathrm{O}_{2}$ dilution method (27).

\section{Analytical procedures}

Plasma glucose was measured with a glucose analyzer (Beckman Instruments, Inc.). Serum insulin (36) and glucagon (37) were determined by radioimmunoassay. Blood urea nitrogen (38) was measured colorimetrically. Urinary nitrogen was measured by the method of Kjeldahl (39). Lactate (40) and pyruvate (41) were measured enzymatically. Fatty acids were determined by gas chromatography (model 5730A; Hewlett-Packard Co., Palo Alto, CA ) as the sum of seven individual fatty acids (myristate, palmitate, palmitoleate, stearate, oleate, linoleate, and arachidonate). Heptadecanoic acid was used as internal standard.

\section{Statistical analysis and calculations}

All data were expressed as the mean \pm SEM. Statistical significance was assessed using ANOVA with repeated measures and Student's twotailed paired or unpaired $t$ test where applicable.

\section{Results}

Euglycemic insulin clamps with and without fat infusion (Fig. 2). In all three studies, insulin infusion raised plasma insulin concentrations from $\sim 5$ to $\sim 70 \mu \mathrm{U} / \mathrm{ml}$. Plasma glucose was clamped at $\sim 85 \mathrm{mg} / \mathrm{dl}$. In the low fatty acid group, plasma FFA decreased from $526 \pm 90$ before to $54 \pm 6 \mu \mathrm{M}$ during insulin infusion. In the medium fatty acid group, FFA concentration was $500 \pm 120$ before and $632 \pm 133 \mu \mathrm{M}$ at the end of the clamp (NS). In the high fatty acid group, FFA concentrations increased from $415 \pm 69$ before to $748 \pm 34 \mu \mathrm{M}$ at the end of the clamp $(P<0.01)$. The three FFA concentration curves (high, medium, and low fatty acid groups) were significantly different from each other (overall comparison of groups by ANOVA with repeated measures $P<0.001$ ).

Leg blood flow rates were $4.0 \pm 0.6,3.8 \pm 0.5$, and $3.9 \pm 0.3$ $\mathrm{ml} / \mathrm{dl}$ leg tissue per min in the low, medium, and high fatty acid groups, respectively. During insulin infusions, leg flow rates increased to $4.7 \pm 0.8,5.7 \pm 0.9$, and $5.7 \pm 0.9 \mathrm{ml} / \mathrm{dl}$, respectively. The differences among the three groups were not statistically significant.

Glucose uptake $\left(G_{R d}\right)$ (Fig. 3, top). $G_{\mathrm{Rd}}$ rose from $\sim 2$ to $\sim 6 \mathrm{mg} / \mathrm{kg}$ per min during the initial $90 \mathrm{~min}$ of insulin infusion in all three groups. Thereafter, $G_{R d}$ in the low, medium, and high fatty acid groups were significantly different from each other (overall comparison of groups). $G_{R d}$ rose further to $\sim 9 \mathrm{mg} / \mathrm{kg}$ per min in the low fatty acid group, stabilized at $\sim 6 \mathrm{mg} / \mathrm{kg}$ per min in the medium fatty acid group, and declined to $\sim 4 \mathrm{mg} / \mathrm{kg}$ per min in the high fatty acid group. Comparing individual time points, the differences between high and low fatty acid groups became significant at $210 \mathrm{~min}$.

Comparing mean values of the last $3 \mathrm{~h}$ (180-360 min) (Fig. 4), $G_{R d}$ declined in a linear fashion with increasing plasma 

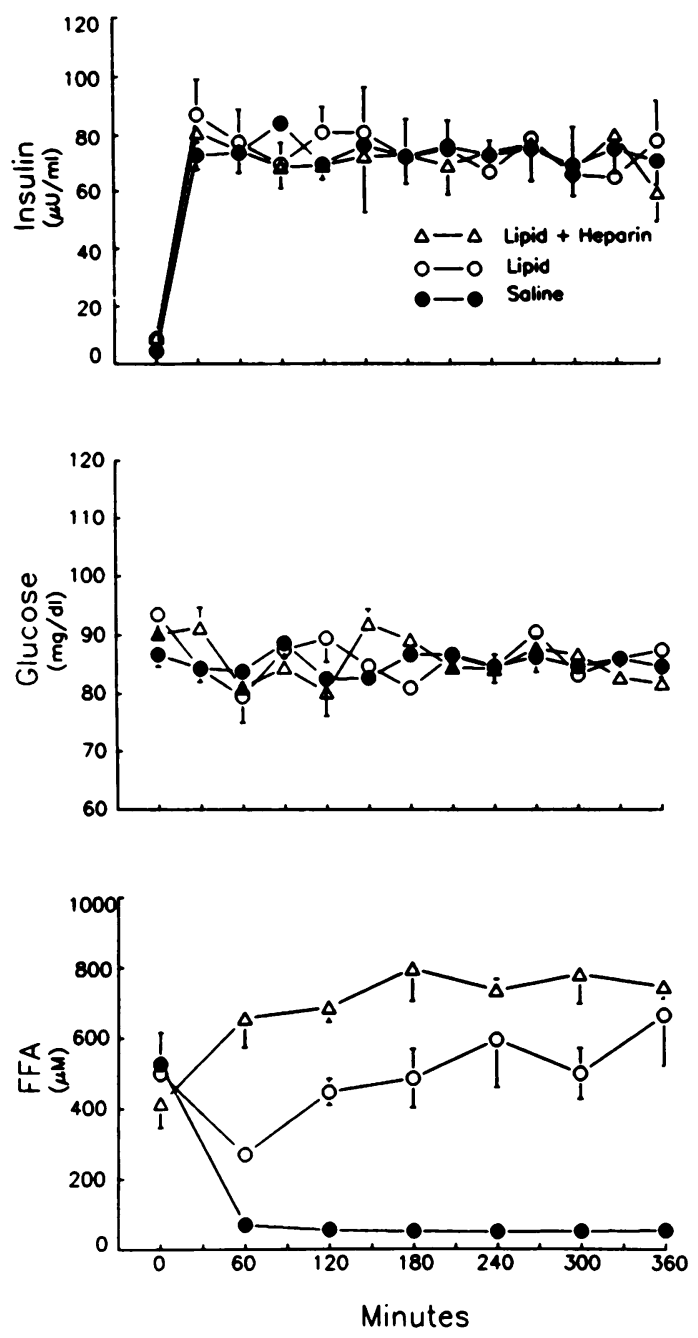

Figure 2. Euglycemic-hyperinsulinemic clamps. Serum insulin concentrations ( $t o p$ ), glucose concentrations (middle), and FFA concentrations (bottom) in healthy volunteers during euglycemic-hyperinsulinemic clamping at high (open triangles, $n=4$ ), medium (open circles, $n=4$ ), and low FFA concentrations (filled circles, $n=6$ ). Shown are mean \pm SE.

FFA concentrations over the entire range of FFA concentrations tested.

Glycogen synthesis (Fig. 3, middle and bottom). Rates of glycogen synthesis (determined as $G_{R d}-$ glycolysis) rose in response to insulin in all three groups. In the low fatty acid group glycogen synthesis increased most (from $0.09 \pm 0.08$ to $5.12 \pm 1.00 \mathrm{mg} / \mathrm{kg}$ per min, $P<0.01$ ), in the medium fatty acid group it increased less (from $0.28 \pm 0.35$ to $3.88 \pm 1.31 \mathrm{mg} / \mathrm{kg}$ per min, $P<0.01$ ), while in the high fatty acid group it increased least (from $0.17 \pm 0.05$ to $1.69 \pm 0.38 \mathrm{mg} / \mathrm{kg}$ per $\mathrm{min}, P$ $<0.05$ ).

Glycogen synthesis rates declined with increasing plasma FFA over the entire range of FFA concentrations tested (Fig. 4).

Glycogen synthesis rates determined on the basis of muscle GS activities measured at in vivo G-6-P and UDPG concentrations yielded similar results. Basal rates of glycogen synthesis combining values from all three groups, however, were slightly higher than values obtained with the noninvasive subtraction method $(1.0 \pm 0.2$ vs $0.2 \pm 0.1 \mathrm{mg} / \mathrm{kg}$ per $\mathrm{min})$. An inhibitory
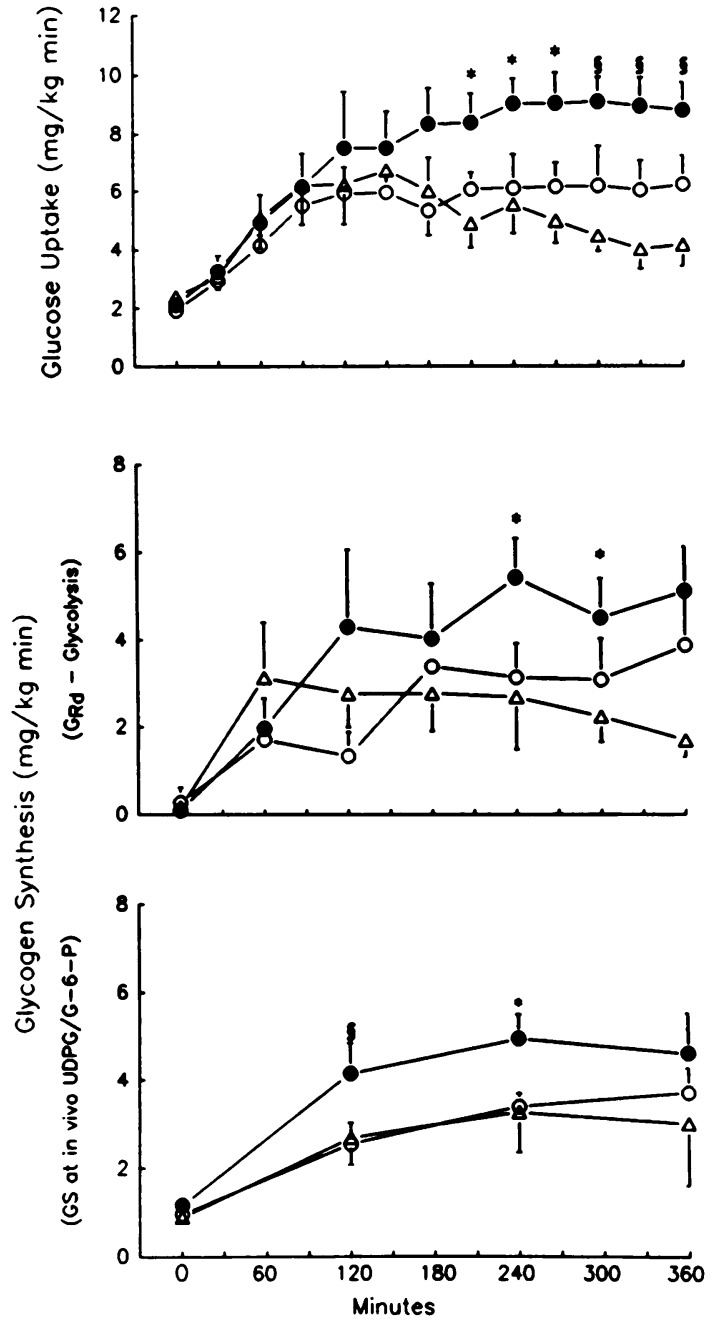

Figure 3. Effect of FFA on glucose uptake and glycogen synthesis. Whole body glucose determined on the basis of muscle GS measurements with in vivo G-6-P/UDPG concentrations (bottom) during euglycemic-hyperinsulinemic clamping at high $(n=4)$, medium ( $n$ $=4)$, and low FFA concentrations $(n=6)$. Shown are mean \pm SE. Symbols as in Fig. 1. Statistical analysis: glucose uptake, overall comparison of groups: $\bullet$ vs $\circ, P<0.01 ; \bullet$ vs $\Delta, P<0.001$; $\circ$ vs $\Delta P$ $<0.03$. Comparison of individual time points: ${ }^{*} P<0.05,{ }^{8} P<0.01$ comparing $\bullet$ vs $\Delta$. Glycogen synthesis $\left(G_{R d}\right.$ minus glycolysis $)$, overall comparison of groups: $\bullet$ vs $\Delta, P<0.05$. Comparison of individual time points: ${ }^{*} P<0.05$, $\bullet$ vs $\Delta$. Glycogen synthesis (GS with in vivo G-6-P/UDPG) overall comparison of groups: $\bullet$ vs $\Delta, P<0.05$. Comparison of individual time points: ${ }^{*} P<0.05,{ }^{8} P<0.01$ comparing $\bullet$ vs $\circ$ and $\Delta$.

effect of fatty acids was apparent at the first biopsy after start of the lipid infusions $(2 \mathrm{~h})$ and continued to be present until the end of the studies in the high but not the medium FFA groups (Fig. 3, bottom).

Glycolysis (Fig. 5, top). Glycolytic flux increased from $2.03 \pm 0.11$ to $3.71 \pm 0.38 \mathrm{mg} / \mathrm{kg}$ per min in the low fatty acid group $(P<0.05)$. No significant changes in glycolytic flux occurred in the medium and in the high fatty acid groups (from $1.65 \pm 0.34$ to $2.36 \pm 0.71 \mathrm{mg} / \mathrm{kg}$ per min and from $2.24 \pm 0.33$ to $2.49 \pm 0.40 \mathrm{mg} / \mathrm{kg}$ per min, respectively).

Glycolytic rates declined significantly between $\sim 50$ and $\sim 550 \mu \mathrm{M}$ FFA. No further decrease was seen with higher ( $750 \mu \mathrm{M}$ ) FFA levels (Fig. 4). 

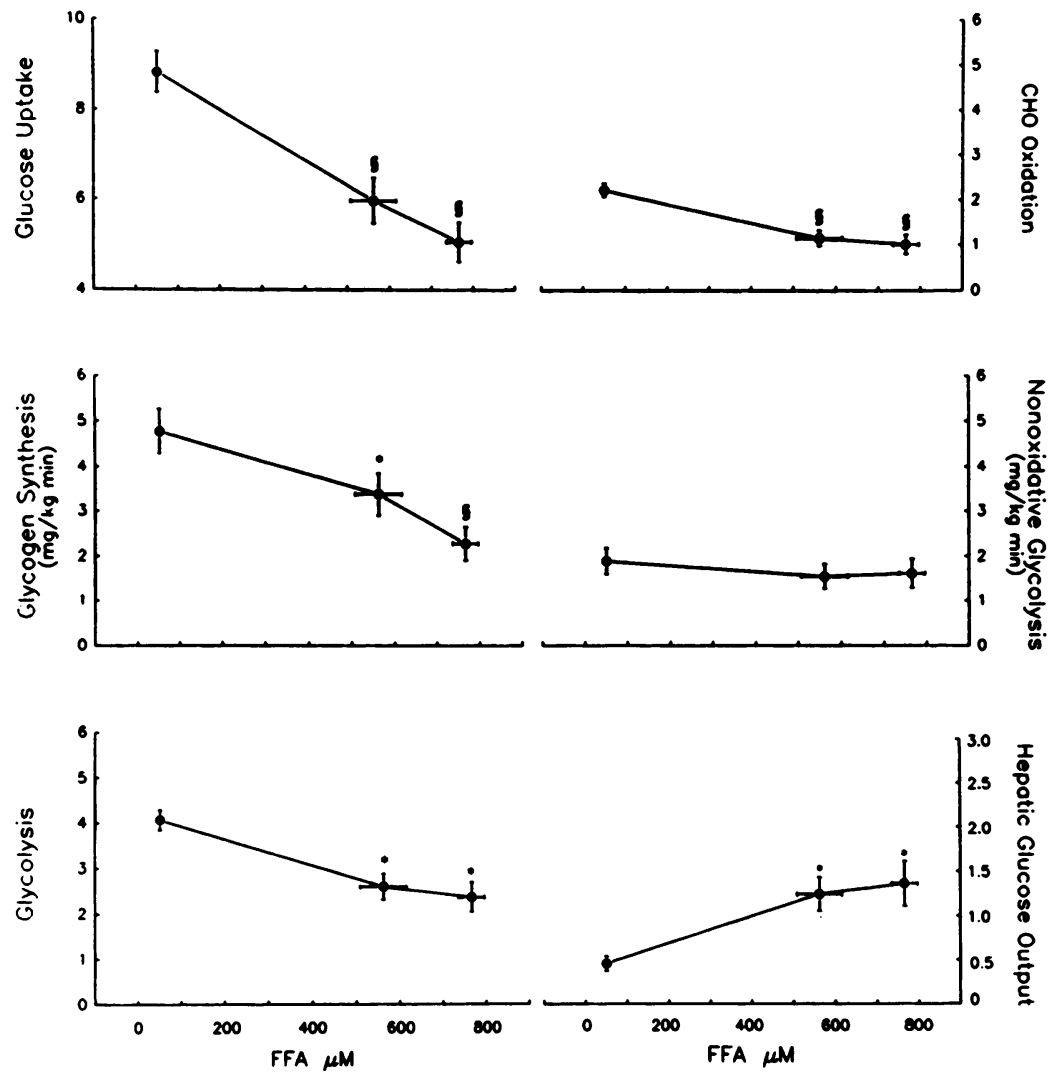

Figure 4. Effects of FFA on CHO metabolism. Effects of three FFA concentrations on whole body rates of glucose uptake (average values from 180 to $360 \mathrm{~min}$ ), glycogen synthesis, glycolysis, CHO oxidation, nonoxidative glycolysis, and HGO during euglycemic-hyperinsulinemic clamping. Shown are mean \pm SE; ${ }^{*} P<0.05,{ }^{8} P<0.01$ comparing low with medium or high FFA values.
CHO oxidation (Fig. 5, middle). Rates of $\mathrm{CHO}$ oxidation increased from $0.63 \pm 0.21$ to $2.33 \pm 0.21 \mathrm{mg} / \mathrm{kg}$ per $\min (P$ $<0.01$ ) in the low fatty acid group. In both medium and high fatty acid groups, $\mathrm{CHO}$ oxidation did not increase significantly above basal values during insulin infusions and remained lower than in the low fatty acid group. These differences became statistically significant at $150 \mathrm{~min}(P<0.05)$.

CHO oxidation rates declined when plasma FFA increased from $51 \pm 5$ to $562 \pm 106 \mu \mathrm{M}(P<0.01)$. There was no further decline in CHO oxidation rates when plasma FFA concentration increased from $562 \pm 106$ to $766 \pm 44 \mu \mathrm{M}$ (Fig. 4).

Nonoxidative glycolysis (Fig. 5, bottom). Basal nonoxidative glycolysis rates were $1.40 \pm 0.26,0.81 \pm 0.45$, and $1.60 \pm 0.39$ $\mathrm{mg} / \mathrm{kg}$ per min in low, medium, and high fatty acid groups, respectively (NS). There were no significant changes in response to insulin or to fatty acids in any of the three groups.

Plasma glucagon and HGO (Fig. 6). There were no signifcant intra- or interstudy changes in plasma glucagon concentrations.

In the low fatty acid group, insulin suppressed HGO virtually completely from $2.26 \pm 0.06$ to $0.29 \pm 0.14 \mathrm{mg} / \mathrm{kg}$ per min (not significantly different from 0 ). In the medium and high fatty acid groups, HGO was significantly less inhibited (from $2.10 \pm 0.27$ to $0.93 \pm 0.12 ;-66 \%$ and from $2.72 \pm 0.56$ to $1.45 \pm 0.46 \mathrm{mg} / \mathrm{kg}$ per min; $-47 \%$, respectively). The differences in $\mathrm{HGO}$ between low and high fatty acid groups became statistically significant at $150 \mathrm{~min}(P<0.02)$. Increasing fatty acid concentration from 550 to $750 \mu \mathrm{M}$ did not further increase HGO (Fig. 4).

Muscle GS (Fig. 7). The $K_{\mathrm{m}}$ of GS activity (Fig. 7, top) declined significantly between 0 and $2 \mathrm{~h}$ in all three groups. In the low and medium fatty acid groups, $K_{\mathrm{m}}$ remained low until the end of the studies. In the high fatty acid group, $K_{\mathrm{m}}$ increased between 4 and $6 \mathrm{~h}$ and at $6 \mathrm{~h}$ had reached preclamp levels.

GS $V_{\max }$ (GS at 7.2 mM G-6-P) (Fig. 7, middle), representing an index of the total amount of enzyme present in muscle, was the same in all three groups and did not change significantly in response to insulin or to fatty acids.

GS fractional velocity (Fig. 7, bottom), the ratio of GS activities at 0.11 and $7.2 \mathrm{mM}$ G-6-P, is considered a good indicator of in vivo enzyme activity. It increased significantly in all three groups in response to insulin between 0 and $4 \mathrm{~h}$. Between 4 and $6 \mathrm{~h}$ GS fractional velocity remained elevated in the low and medium, but declined significantly in the high fatty acid group.

Muscle glycogen phosphorylase and G-6-P (Table II). Glycogen phosphorylase $a$ activities did not change significantly in response to insulin or to insulin plus fatty acids in any of the three groups.

There were no statistically significant changes in G-6-P concentrations in any of the three groups between 0 and $4 \mathrm{~h}$. Between 4 and $6 \mathrm{~h}, \mathrm{G}-6-\mathrm{P}$ increased significantly in the high fatty acid group $(P<0.05)$, while it remained unchanged in the low and medium fatty acid groups.

\section{Discussion}

FFA/CHO metabolism dose effect relationships. In this study, we have examined effects of three steady state plasma fatty acid concentrations on the ability of insulin to promote glucose uptake and on the rate of intracellular glucose utilization, i.e., glycogen synthesis and glycolysis. As $>\mathbf{8 0 \%}$ of the glucose infused intravenously has been shown to be taken up by muscle (42), our results provided information primarily on the effects of FFA on muscle metabolism. 

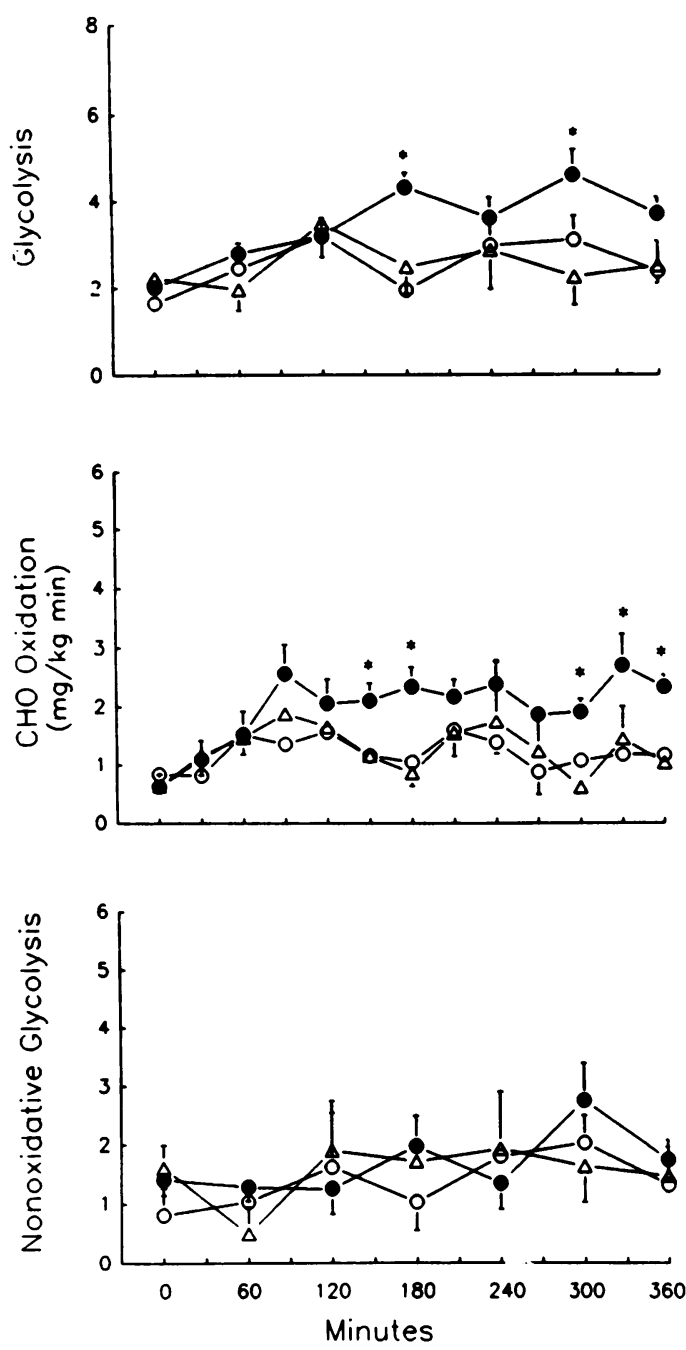

Figure 5. Effect of FFA on glycolysis, CHO oxidation, and nonoxidative glycolysis. Whole body rates of glycolysis, $\mathrm{CHO}$ oxidation, and nonoxidative glycolysis during euglycemic-hyperinsulinemic clamping at high, medium, and low FFA concentrations. Symbols and number of experiments as in Fig. $1 .{ }^{*} P<0.05$ comparing values at low and high FFA concentrations.

There was a dose-dependent relationship between plasma FFA concentrations and glucose uptake. $G_{R d}$ decreased by $\sim 50 \%$ (from 8.8 to $4.2 \mathrm{mg} / \mathrm{kg}$ per $\mathrm{min}$ ) when FFA concentrations rose from $\sim 50$ to $\sim 750 \mu \mathrm{M}$ (Figs. 3 and 4 ). Overall, the major part $(\sim 2 / 3)$ of the decline in $\mathrm{G}_{\mathrm{Rd}}$ was caused by reduction in the rate of glycogen synthesis, and a minor part $(\sim 1 / 3)$ was caused by reduction in the rate of $\mathrm{CHO}$ oxidation. The decrease in $G_{R d}$ of $\sim 3 \mathrm{mg} / \mathrm{kg}$ per min which occurred when FFA concentrations rose from $\sim 50$ to $\sim 500 \mu \mathrm{M}$ was accounted for equally by decreases in $\mathrm{CHO}$ oxidation and glycogen synthesis, while the decline in $G_{R d}$ which occurred when plasma FFA concentrations rose further (from $\sim 550$ to $\sim 750 \mu \mathrm{M}$ ) was caused exclusively by a decrease in glycogen synthesis. These findings expanded earlier observations (13, 43) that the effect of fat on $\mathrm{CHO}$ oxidation was relatively small and that the main problem in obese diabetic and nondiabetic subjects, whose FFA concentrations are commonly $>500 \mu \mathrm{M}$, was a defect in nonoxidative glucose disposal (1-9).
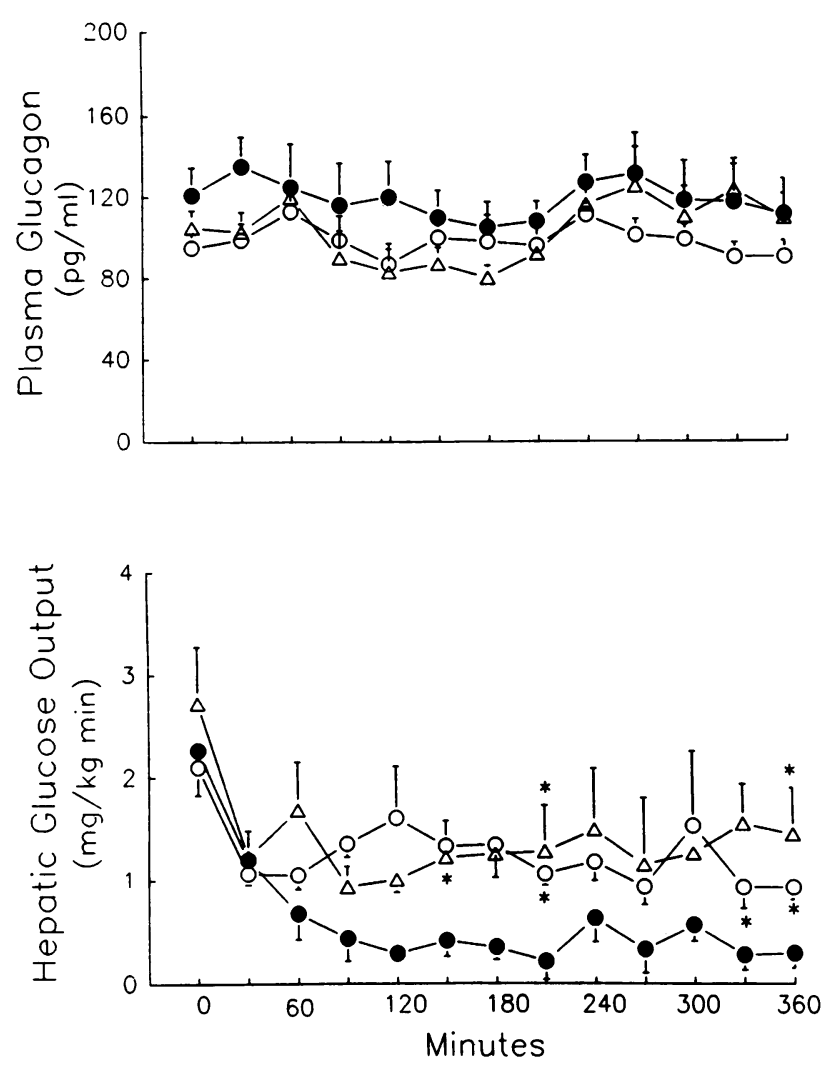

Figure 6. Plasma glucagon and HGO. Effect of euglycemic-hyperinsulinemic clamping at high, medium, and low FFA concentrations on plasma glucagon concentration and on rates of HGO. Number of subjects and symbols as in Fig. $1 .{ }^{*} P<0.05$ comparing high or medium with low FFA concentrations.

Time course and mechanisms of FFA effects. The inhibition of $\mathrm{CHO}$ oxidation appeared early, was largest at postabsorptive FFA concentrations $(\sim 550 \mu \mathrm{M})$, and, as we have previously demonstrated, was associated with a four- to fivefold increase in muscle acetyl-CoA content (15). Acetyl-CoA is well known to inhibit pyruvate dehydrogenase (PDH) activity. Moreover, Kelley et al. (16) have shown recently that fat infusion induced inhibition of PDH in normal volunteers. Present evidence, therefore, supports the notion that fat infusion decreases $\mathrm{CHO}$ oxidation in skeletal muscle by acetyl-CoA-induced inhibition of PDH activity. This may, however, not be the only mechanism, as there was evidence that fatty acids may have lowered glucose transport or phosphorylation (see below) which would have also reduced $\mathrm{CHO}$ oxidation.

The present study provided evidence for the presence of two independent mechanisms for the inhibition of glycogen synthesis. First, as reported previously by us (15) and confirmed recently by others (16), fat infusion abolished insulin stimulation of GS activity in skeletal muscle. We have now extended our earlier observations by demonstrating that the inhibition of GS occurred late, i.e., after 4-6 h of fat infusion, was seen only at high FFA concentrations $(\sim 750 \mu \mathrm{M})$, and was associated with an increase in muscle G-6-P content. The cause for the inhibition of GS remained uncertain but may have been related to an increase in long chain acetyl-CoA and/ or glycogen concentrations. Both have been shown to suppress glycogen synthesis $(44,45)$. Serial measurements in plasma 

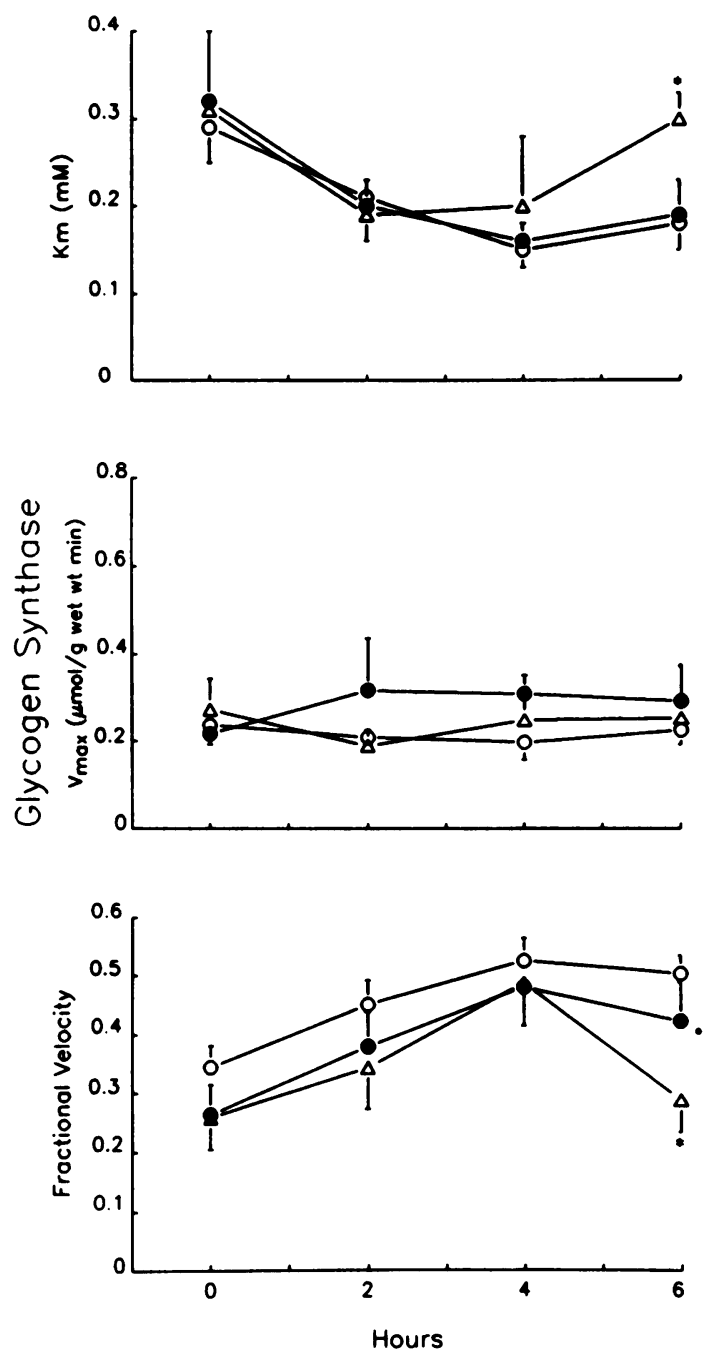

Figure 7. Effect of FFA on muscle GS. Effect of euglycemic-hyperinsulinemic clamping at high, medium, and low FFA concentrations on GS $K_{\mathrm{m}}$ (mM UDPG), $V_{\max }$, and fractional velocity $(0.11 / 0.72$ mM G-6-P). Symbols and number of subjects as in Fig. $1 .{ }^{*} P<0.05$ comparing high and low FFA concentrations.

and muscle biopsy samples revealed, however, that glycogen synthesis was already inhibited before inhibition of muscle GS activity. This indicated the presence of an additional, earlier fatty acid-induced block of glycogen synthesis which was unrelated to an impairment of GS. Glycogen synthesis depends primarily on the activity of the rate-limiting enzyme GS and the availability of its main substrate G-6-P/UDPG. The observed reduction of glycogen synthesis associated with normal GS activity, therefore, suggested that fatty acids had lowered G-6-P/UDPG levels in skeletal muscle. This suggestion was supported when rates of glycogen synthesis were determined in vitro with in vivo G-6-P and UDPG concentrations (Fig. 3, bottom), and a significant suppression of glycogen synthesis was apparent at the first muscle biopsy after start of the fat infusion, i.e., at $2 \mathrm{~h}$. Together, our data provided evidence that a decrease in G-6-P/UDPG, probably produced by fatty acidmediated inhibition of glucose transport or phosphorylation, was responsible for a major defect in glycogen synthesis. Supporting this notion, Hardy et al. (46) have reported recently
Table II. Effects of Fatty Acids on Glycogen Phosphorylase a and on G-6-P Concentration in Skeletal Muscle

\begin{tabular}{lcccc}
\hline & \multicolumn{5}{c}{ Hours } \\
\cline { 2 - 5 } & 0 & 2 & 4 & 6 \\
\hline & \multicolumn{4}{c}{$\mu$ mol/g wet wt per min } \\
Glycogen phosphorylase $a$ & & & & \\
Low fatty acids & $2.9 \pm 0.6$ & $3.2 \pm 0.5$ & $3.0 \pm 0.4$ & $3.1 \pm 0.2$ \\
Medium fatty acids & $3.3 \pm 1.5$ & $2.6 \pm 0.7$ & $2.9 \pm 0.9$ & $3.1 \pm 0.9$ \\
High fatty acids & $3.5 \pm 0.5$ & $3.3 \pm 1.6$ & $2.6 \pm 0.7$ & $2.5 \pm 0.5$ \\
& & $n$ nmol/g wet wt & \\
G-6-P & & & & \\
Low fatty acids & $79 \pm 19$ & $101 \pm 30$ & $109 \pm 31$ & $96 \pm 16$ \\
Medium fatty acids & $74 \pm 26$ & $57 \pm 18$ & $78 \pm 19$ & $105 \pm 11$ \\
High fatty acids & $56 \pm 10$ & $84 \pm 11$ & $69 \pm 13$ & $139 \pm 29 *$ \\
& & & & \\
\hline
\end{tabular}

* $P<0.05$ compared with values at 0,2 , and $4 \mathrm{~h}$.

that 1-2 mM palmitic acid inhibited insulin-stimulated 3-Omethyl glucose transport into rat soleus muscle.

Nonoxidative glycolysis. Independent determination of glycolysis and $\mathrm{CHO}$ oxidation allowed us to calculate rates of nonoxidative glycolysis, which consists essentially of lactate and alanine production rates. Our data suggested that neither insulin nor fat infusion affected nonoxidative glycolysis, which remained at $\sim 1-1.5 \mathrm{mg} / \mathrm{kg}$ per min during all three studies. These findings are in accord with those of Consoli et al. (47) who reported postabsorptive lactate and alanine production rates of $\sim 1.4 \mathrm{mg} / \mathrm{kg}$ per min in normal volunteers. They are also in agreement with data showing that insulin has little or no effect on lactate and alanine release from resting muscle (16, 48,49 ). Our data do not exclude a small increase in lactate accompanied by a decrease in alanine production in response to lipid infusion as has been observed by Kelley et al. (16) in arterio-venous balance studies across forearm muscle.

$H G O$. Confirming reports by others $(14,17,50)$, we found that lipid infusions interfered with insulin's suppressive effect on HGO, i.e., caused hepatic insulin resistance. The present study showed, in addition, that this effect appeared early and seemed greatest at postabsorptive FFA concentrations $(\sim 550 \mu \mathrm{M})$.

The mechanisms responsible for this effect were not studied but could have been related to elevated plasma concentrations of FFA, glycerol, or both. Lipolysis from the infused fat resulted in increased production of fatty acids and glycerol, resulting not only in higher FFA but also in higher glycerol concentrations $(4.5 \pm 0.6$ vs $3.8 \pm 0.2$ vs $1.2 \pm 0.4 \mathrm{mg} / \mathrm{dl}$, respectively, in high, medium, and low FFA studies). Putative mechanisms for the lipid effect on HGO include enhanced $\beta$ oxidation of fatty acids which provides ATP, i.e., the energy needed to drive gluconeogenesis, as well as acetyl-CoA which activates pyruvate carboxylase, the first key enzyme in the gluconeogenetic pathway (51), and increased availability of glycerol which is an excellent substrate for gluconeogenesis (52).

Fatty acids and insulin clearance. Despite large differences in plasma FFA concentrations (from 50 to $750 \mu \mathrm{M}$ ), steady state serum insulin concentrations, produced by continuous infusion of insulin at a rate of $1 \mathrm{mU} / \mathrm{kg}$ per min, were the same in all three groups. These data do not support the hypothesis 
that elevated FFA concentrations interfere with hepatic degradation of insulin and thus are responsible, at least in part, for the hyperinsulinemia seen in obese diabetic and nondiabetic individuals (for review see reference 53).

Physiological relevance. Impaired insulin stimulation of glucose storage and GS activity and increased hepatic glucose production have been consistent findings in obese diabetic and nondiabetic individuals. The demonstration that FFA suppressed insulin-stimulated glucose uptake and that the products of lipolysis, i.e., FFA and glycerol, increased hepatic glucose production supported the notion that abnormal fat metabolism, perhaps superimposed on genetic abnormalities $(7,54$, 55), may account for much of the peripheral and hepatic insulin resistance of obese diabetic and nondiabetic subjects.

The observation that FFA inhibited glucose uptake in a dose-dependent fashion throughout the physiologic range of plasma FFA concentrations suggested further that for every lowering in plasma FFA, regardless of the ambient FFA level, there would be a corresponding decrease in insulin resistance. This could perhaps be exploited by treating insulin-resistant diabetic patients with antilipolytic agents.

\section{Acknowledgments}

We thank the nurses of the General Clinical Research Center for assistance with the clinical studies; Maria Mozzoli, Karen Davis, and Gary Sebel for technical assistance; and Constance Harris for typing the manuscript.

This study was supported by a Clinical Research Center Grant from the American Diabetes Association (G. Boden), by National Institutes of Health grants R01-AG-07988 (G. Boden), R01-DK-47477 (L. Rossetti), and R029-DK-42177 (L. Rossetti), and grant RR 00349 (General Clinical Research Center) from Temple University Hospital.

\section{References}

1. DeFronzo, R. A., R. C. Bonadonna, and E. Ferrannini. 1992. Pathogenesis of NIDDM. A Balanced Overview. Diabetes Care. 15:318.

2. Boden, G., T. K. Ray, R. H. Smith, and O. E. Owen. 1983. Carbohydrate oxidation and storage in obese non-insulin dependent diabetic patients. Effects of improving glycemic control. Diabetes. 32:982-987.

3. Damsbo, P., A. Vaag, O. Hother-Nielsen, and H. Beck-Nielsen. 1991. Reduced glycogen synthase activity in skeletal muscle from obese patients with and without type 2 (non-insulin dependent) diabetes mellitus. Diabetologia. 34:239245.

4. Kelley, D. E., and L. J. Mandarino. 1990. Hyperglycemia normalizes insulin-stimulated skeletal muscle glucose oxidation and storage in non-insulin-dependent diabetes mellitus. J. Clin. Invest. 86:1999-2007.

5. Johnson, A. B., M. Argyraki, J. C. Thow, D. Broughton, I. R. Jones, and R. Taylor. 1990. Effects of intensive dietary treatment on insulin-stimulated skeletal muscle glycogen synthase activation and insulin secretion in newly presenting type 2 diabetic patients. Diabetic Medicine. 7:420-428.

6. Thorburn, A. W., B. Gumbiner, F. Bulacan, G. Brechtel, and R. R. Henry. 1991. Multiple defects in muscle glycogen synthase activity contribute to reduced glycogen synthesis in non-insulin-dependent diabetes mellitus. J. Clin. Invest. 87:489-495.

7. Eriksson, J., A. Franssila-Kallunki, A. Ekstrand, C. Saloranta, E. Widen, C. Schalin, and L. Groop. 1989. Early metabolic defects in persons at increased risk for non-insulin-dependent diabetes mellitus. N. Engl. J. Med. 321:337-343.

8. Vaag, A., J. E. Henriksen, and H. Beck-Nielsen. 1992. Decreased insulin activation of glycogen synthase in skeletal muscles in young nonobese Caucasian first degree relatives of patients with non-insulin-dependent diabetes mellitus. $J$. Clin. Invest. 89:782-788.

9. Shulman, G. I., D. L. Rothman, T. Jue, P. Stein, R. A. DeFronzo, and R. G. Shulman. 1990. Quantitation of muscle glycogen synthesis in normal subjects and subjects with non-insulin-dependent diabetes by ${ }^{13} \mathrm{C}$ nuclear magnetic resonance spectroscopy. N. Engl. J. Med. 322:223-228.

10. McGarry, J. D. 1992. What if Minkowski had been ageusic? An alternative angle on diabetes. Science (Wash. DC). 258:766-770.

11. Randle, P. J., P. B. Garland, E. A. Newsholme, and C. N. Hales. 1965. The glucose fatty acid cycle in obesity and maturity onset diabetes mellitus. Ann. NY Acad. Sci. 131:324-333.

12. Reaven, G. M., C. Hollenbeck, C.-Y. Jeng, M. S. Wu, and Y.-D. Chen. 1988. Measurement of plasma glucose, free fatty acid, lactate and insulin for $24 \mathrm{~h}$ in patients with NIDDM. Diabetes. 37:1020-1024.

13. Thiebaud, D., R. A. DeFronzo, E. Jacot, A. Golay, K. Acheson, E. Maeder, E. Jequier, and J.-P. Felber. 1982. Effect of long chain triglyceride infusion on glucose metabolism in man. Metab. Clin. Exp. 31:1128-1136.

14. Ferrannini, E., E. J. Barrett, S. Bevilacqua, and R. A. DeFronzo. 1983. Effect of fatty acids on glucose production and utilization in man. J. Clin. Invest. 72:1737-1747.

15. Boden, G., F. Jadali, J. White, Y. Liang, M. Mozzoli, X. Chen, E. Coleman, and C. Smith. 1991. Effects of fat on insulin-stimulated carbohydrate metabolism in normal men. J. Clin. Invest. 88:960-966.

16. Kelley, D. E., M. Mokan, J.-A. Simoneau, and L. J. Mandarino. 1993. Interaction between glucose and free fatty acid metabolism in human skeletal muscle. J. Clin. Invest. 92:91-98.

17. Saloranta, C., V. Koivisto, E. Widen, K. Falholt, R. A. DeFronzo, M. Harkonen, and L. Groop. 1993. Contribution of muscle and liver to glucose-fatty acid cycle in humans. Am. J. Physiol. 264:E599-E605.

18. Bevilacqua, S., R. Bonadonna, G. Buzzigoli, C. Boni, D. Ciociaro, F. Maccari, M. A. Giorico, and E. Ferrannini. 1987. Acute elevation of free fatty acid levels leads to hepatic insulin resistance in obese subjects. Metab. Clin. Exp. 36:502-506.

19. Wolfe, B. M., S. Klein, E. J. Peters, B. F. Schmidt, and R. R. Wolfe. 1988 Effect of elevated free fatty acids on glucose oxidation in normal humans. Metab. Clin. Exp. 37:323-329.

20. Gulli, G., E. Ferrannini, M. Stern, S. Haffner, and R. A. DeFronzo. 1992. The metabolic profile of NIDDM is fully established in glucose-tolerant offspring of two Mexican-American NIDDM parents. Diabetes. 41:1575-1586.

21. Richter, E. A., S. A. Hansen, and B. F. Hansen. 1989. Mechanisms limiting glycogen storage in muscle during prolonged insulin stimulation. Am. J. Physiol. 255:E621-E628.

22. Shimoyama, R., T. K. Ray, C. R. Savage, Jr., O. E. Owen, and G. Boden. 1984. In vivo and in vitro effects of antiinsulin receptor antibodies. J. Clin. Endocrinol. \& Metab. 59:916-923.

23. Molina, J. M., A. D. Baron, S. V. Edelman, G. Brechtel, P. Wallace, and J. M. Olefsky. 1990. Use of a variable tracer infusion method to determine glucose turnover in humans. Am. J. Physiol. 258:E16-E23.

24. Steele, R., J. S. Wall, R. C. DeBodo, and N. Altszuler. 1956. Measurement of size and turnover rate of body glucose pool by the isotope dilution method. Am. J. Physiol. 187:15-24.

25. Rossetti, L., and A. Giaccari. 1990. Relative contribution of glycogen synthesis and glycolysis to insulin-mediated glucose uptake. A dose-response euglycemic clamp study in normal and diabetic rats. J. Clin. Invest. 85:1785-1792.

26. Rossetti, L., Y.-T. Lee, J. Ruiz, S. C. Aldridge, H. Shamoon, and G. Boden. 1993. Quantitation of glycolysis and skeletal muscle glycogen synthesis in humans. Am. J. Physiol. 265:E761-E769.

27. Goldman, R. F., and E. R. Buskirk. 1961. Body volume measurement by underwater weighing: description of a method. In Techniques for Measuring Body Composition. National Research Council, National Academy of Science. Washington, DC. 78-89.

28. Owen, O. E., V. E. Trapp, G. A. Reichard, Jr., M. A. Mozzoli, R. Smith and G. Boden. 1980. Effects of therapy on the nature and quantity of fuels oxidized during diabetic ketoacidosis. Diabetes. 29:365-372.

29. Tappy, L., O. E. Owen, and G. Boden. 1988. Effect of hyperinsulinemia on urea pool size and substrate oxidation rates. Diabetes. 37:1212-1216.

30. Michal, G. 1985. D-Glucose-6-phosphate. In Methods of Enzymatic Analysis. H. U. Bergmeyer, editor. VCH, Weinheim, Germany. 191-198.

31. Rossetti, L., S. Farrace, S. B. Choi, A. Giaccari, L. Sloan, S. Frontoni, and M. S. Katz. 1993. Multiple metabolic effects of CGRP in conscious rats: role of glycogen synthase and phosphorylase. Am. J. Physiol. 264:E1-E10.

32. Rossetti, L., and M. R. Laughlin. 1989. Correction of chronic hyperglycemia with vanadate, but not phlorizin, normalizes in vivo glycogen repletion and in vitro glycogen synthase activity in diabetic skeletal muscle. J. Clin. Invest. 84:892-899.

33. Thomas, J., K. Schlender, and J. Larner. 1968. A rapid filter paper assay for UDP glucose-glycogen glucosyltransferase, including an improved biosynthesis of UDP- ${ }^{14} \mathrm{C}$-glucose. Anal. Biochem. 25:486-499.

34. Kochan, R. G., D. R. Lamb, S. A. Lutz, C. V. Perrill, E. M. Reimann, and K. K. Schlender. 1979. Glycogen synthase activation in human skeletal muscle: effects of diet and exercise. Am. J. Physiol. 236:E660-E666.

35. Sumner, D. S. 1982. Mercury strain-gauge plethysmography. In Non-invasive Diagnostic Techniques in Vascular Disease. E. F. Bernstein, editor. C. V. Mosby Co., St. Louis, MO. 117-135.

36. Soeldner, J. S., and D. Slone. 1965. Critical variables in the radioimmunoassay of serum insulin using the double antibody technic. Diabetes. 14:771-779.

37. Harris, G., G. R. Faloona, and R. H. Unger. 1979. Glucagon. In Methods of Hormone Radioimmunoassay. B. M. Jaffe and H. R. Behrmann, editors. Academic Press, Inc., New York. 643-656. 
38. Marsh, W. H., B. Fingerhut, and H. Miller. 1965. Automated and manual direct method for the determination of blood urea. Clin. Chem. 11:624-627.

39. Hawk, P. 1947. The Kjeldahl method. In Practical Physiological Chemistry. The Blakiston Company, Toronto. 814-822.

40. Hohorst, H. J. 1965. Lactate. In Methods of Enzymatic Analysis. H. U. Bergmeyer, editor. Academic Press, Inc., New York. 266.

41. Bucher, T., R. Czok, W. Lampbrecht, and E. Latzkco. 1959. Pyruvate. In Methods of Enzymatic Analysis. H. U. Bergmeyer, editor. Academic Press, Inc., New York. 253.

42. DeFronzo, R. A., E. Jacot, E. Jequier, E. Maeder, J. Wahren, and J. P. Felber. 1981. The effect of insulin on the disposal of intravenous glucose; results from indirect calorimetry and hepatic and femoral venous catheterization. Diabetes. 30:1000-1007.

43. Groop, L. C., R. C. Bonadonna, M. Shank, A. S. Petrides, and R. A. DeFronzo. 1991. Role of free fatty acids and insulin in determining free fatty acid and lipid oxidation in man. J. Clin. Invest. 87:83-89.

44. Wititsuwannakul, D., and K.-H. Kim. 1977. Mechanism of palmityl coenzyme A inhibition of liver glycogen synthase. J. Biol. Chem. 252:7812-7817.

45. Danforth, W. 1965. Glycogen synthetase activity in skeletal muscle. J. Biol. Chem. 240:588-593.

46. Hardy, R. W., J. H. Ladenson, E. J. Henriksen, J. O. Holloszy, and J. M. McDonald. 1991. Palmitate stimulates glucose transport in rat adipocytes by a mechanism involving translocation of the insulin sensitive glucose transporter (Glut 4). Biochem. Biophys. Res. Commun. 177:343-349.

47. Consoli, A., N. Nurjhan, J. J. Reilly, D. M. Bier, and J. E. Gerich. 1990. Mechanism of increased gluconeogenesis in non-insulin-dependent diabetes mellitus. Role of alterations in systemic, hepatic, and muscle lactate and alanine metabolism. J. Clin. Invest. 86:2038-2045.
48. Consoli, A., N. Nurjahan, J. Gerich, and L. Mandarino. 1992. Skeletal muscle in a major site of lactate uptake and release during hyperinsulinemia. Metab. Clin. Exp. 41:176-179.

49. Natali, A., G. Buzzigoli, S. Taddei, D. Santoro, M. Cerri, R. Pedrinelli, and E. Ferrannini. 1990. Effects of insulin on hemodynamics and metabolism in human forearm. Diabetes. 39:490-500.

50. Fanelli, C., S. Calderone, L. Epifano, A. De Vincenzo, F. Modarelli, S. Pampanelli, G. Perriello, P. De Feo, P. Brunetti, J. E. Gerich, and G. B. Bolli. 1993. Demonstration of a critical role for free fatty acids in mediating counterregulatory stimulation of glucogenogenesis and suppression of glucose utilization in humans. J. Clin. Invest. 92:1617-1622.

51. Williamsson, J. R., R. A. Kreisberg, and P. W. Felts. 1966. Mechanisms for the stimulation of gluconeogenesis by fatty acids in perfused rat liver. Proc. Natl. Acad. Sci. USA. 6:247-254.

52. Nurjhan, N., P. J. Campbell, F. P. Kennedy, J. M. Miles, and J. E. Gerich. 1986. Insulin dose-response characteristics for suppression of glycerol release and conversion to glucose in humans. Diabetes. 35:1326-1331.

53. Kolaczynski, J. W., and G. Boden. 1993. Effects of oleate and fatty acids from omental adipocytes on insulin uptake in rat liver cells. Endocrinology. 133:2871-2874.

54. Wells, A. M., I. C. Sutcliffe, A. B. Johnson, and R. Taylor. 1993. Abnormal activation of glycogen synthesis in fibroblasts from NIDDM subjects. Evidence of an abnormality specific to glucose metabolism. Diabetes. 42:583-589.

55. Vestergaard, H., C. Bjorbaek, P. H. Andersen, J. F. Bak, and O. Pedersen. 1991. Impaired expression of glycogen synthase mRNA in skeletal muscle of NIDDM patients. Diabetes. 40:1740-1745. 